\title{
Energy Security Centres in support of the development of a comprehensive EU Energy Policy
}

\author{
K. Nagy ${ }^{1, *}$, K. Körmendi ${ }^{2}$ \\ ${ }^{1}$ Special Advisor, Triones Institute of Technology, Budapest, Hungary \\ ${ }^{2}$ Phd student, Zrínyi Miklós National Defense University, Budapest, Hungary \\ * Corresponding author. Tel: +36 305350951, E-mail: knagy794@t-email.hu
}

\begin{abstract}
There are paradoxes and contradictions in the interpretation of the concept of energy security among the micro sphere (the level of business organizations and individual users), the macro sphere and the global level. For example, in the global interpretation it is no longer sufficient to focus on meeting objective social needs for energy alone. We should also take into consideration the environmental impacts of meeting these needs (global warming, climate change etc.) as well as sustainability. We need to adopt a comprehensive approach at the level of our energy security policy as well. This may be effectively supported by Energy Security Centers (ESC), which are virtual energy security knowledge centers. The essay analyses the issues for consideration listed in the “Stock taking document - Towards a new Energy Strategy for Europe 2011-2020" from the aspect of the possible application of ESCs to the solution and support of these issues and proposes the EU level establishment of ESCs. Based on the analysis of the stock taking document, the aim of the study is to highlight the advantages resulting from the institution of an European network of knowledge centres (Energy Security Centres) for the implementation of the European Energy Policy.
\end{abstract}

Keywords: Energy policy, Energy Security Centres, European Union

\section{Introduction}

The authors' research in the field of energy security has revealed the necessity of the establishment of energy security centres to facilitate the knowledge management support of the solution of energy security problems. Regarding their basic nature, energy security centres function as virtual energy security centres. In a legal sense, they are autonomous public administration institutions. By autonomous public administration institutions we mean institutions like agencies of various profile in the United States, directly subordinated to Congress. This legal status along with normative financing ensures the independence of these institutions, which is a prerequisite for authentic operation. According to our concept [1], the main role of such an Energy Security Centre (ESC) is to provide authentic information to aid the solution of energy security problems and to create the conditions required for decision makers to use this authentic information effectively in practice. With the help of knowledge centres it also becomes possible to place the knowledge transfer supporting energy security on qualitatively new foundations. The authors hold that the establishment of knowledge centres and the development of a knowledge centre network open up new opportunities in the interactive development and implementation of the comprehensive energy policy of the European Union.

The study points out the issues for consideration listed in the Stock taking document towards EU Energy Strategy for the period 2011 - 2020 [2] where the application of knowledge centres is of outmost importance. Based on a background analysis, the study considers the most important advantages resulting from the functionality of ESCs, points out the most important aspects of developing an ESC network, and makes specific recommendations regarding its establishment. 


\section{The Role of Energy Security Centres: A Comprehensive Approach}

\subsection{The Functionality of Energy Security Centres}

Former inquiries regarding the concept of energy security reveal that there are paradoxical contradictions among micro level, macro level and global interpretations. [3] As a result, certain statements which may be true using a given approach, for example at the level of the micro sphere, will not hold if we apply a macro level or global approach. It is becoming more and more typical that even the management of relatively simple, local problems requires a global approach.

With reference to the above study we should mention that the interpretation belonging to the micro sphere, in other words to the world of companies and organization, starts out from a threat to the satisfaction of our demands for energy and applies a supply security centred approach. The macro level interpretation of energy security focuses on issues related to the satisfaction of the objective energy needs of a given society. The global interpretation examines the question of need satisfaction in close connection with the results of the satisfaction of needs. It takes into consideration that the method of need satisfaction will have an impact on the possibility of the satisfaction of future needs.

Accordingly, the complete satisfaction of energy demands in a given country by no means guarantees that objective energy needs in that country are also completely satisfied, or saturated. The recognition of needs and their transformation into demand is influenced by a number of distorting factors. The most important of such factors are related to our shortcomings in recognizing these needs and the impact of various interests on demands. The recognition of needs is a task for science, while the transformation of these needs into goals is a political task, and the determination of specific demands belongs to the realm of the market and the economic interests in play. These three areas are characterized by close interaction and a contradictory relationship with each other. What they all have in common is that none of them can exist without authentic factual information. The importance of the need for factual information is well illustrated by an EU Commission Staff Working Document [4], which states the following:

"The problem that requires action is the lack of consistent data and information on investment projects (in their different phases) and the related shortcomings. EU institutions lack relevant/consistent data on the development of energy infrastructure in the EU to assess the strategic supply/demand balance. Industry is potentially affected by insufficient transparency on the likely evolution of the EU energy system.” [4]

The solution of energy security problems through the application of a global approach may be effectively supported by energy security centres. [1] Regarding their basic nature, energy security centres are virtual energy security centres with the following functionality:

A) Fast and efficient output of new knowledge and information required for competent energy-related policy-making, energy-related developments, environment statutes, etc.

B) Acceleration of the acquisition of practical knowledge required for competent energy related policy-making, implementation of policy guidelines and for the identification of specific problems arising in connection with energy security.

C) Creation, maintenance and continuous improvement of a platform designed for the efficient transfer of knowledge; establishment of foundations with completely new 
characteristics, to be used in addressing energy security issues in order to provide best practice methodology.

The application of modern ICT solutions and knowledge management to support the implementation of energy policies and the solution of energy security problems is not a unique idea. For example, we should mention the book edited by M. Bazilian and F. Roques [5] and the work of K. Metaxiotis [6] The concept of ESCs is different from the approaches appearing in these works and various other publications in a sense that it treats the creation of the authentic spatial information required for problem solving, the development of the capacities required for the effective use of information, and knowledge transfer as part of the same system.

The realization of the basic functions of energy security centres in accordance with the above is relevant not only to the solution of specific energy security problems but the implementation of energy policies as well. A network of energy security centres covering EU member states would be able to provide effective support to the implementation of a comprehensive EU Energy Policy. In the following we will discuss the role of a network of energy security centers in the implementation of the Stock Taking Document [2].

\subsection{The basic concept of the "Stock Taking Document"}

An analysis of the Stock Taking Document reveals that the approach used at its drafting reflects what we have referred to as a global approach. The document addresses the following issue:

"Completing the internal energy market, achieving energy savings and promoting lowcarbon innovation are the main vectors to reach the objectives of competitiveness, sustainability and security of supply. A well functioning internal market, based on regional and pan-European interconnections, will serve all consumers, ensure energy security and allow the transition towards a low-carbon electricity system. There remains large scope for cost-efficient energy saving measures in order to reduce greenhouse gas emissions; energy savings also lower the energy bill and reduce dependence on energy imports. Finally innovation will be essential to make our energy system sustainable and to renew Europe's manufacturing base and create green jobs.” [2]

In other words, the Stock Taking Document aims to resolve the contradictions between supply objectives based on demand and objective needs, and states that there is a need for the recognition and exploitation of the connections between existing needs and the consequences of the satisfaction of these needs.

The Stock Taking Document lists the key issues of Energy Strategy for Europe 2011-2020 as well as the priority areas for the future strategy. They are the following [2]:

o Modern integrated grids

o Making progress towards a low-carbon energy system

o Leadership in technological innovation

o A strong and coordinated external energy policy

o Protecting EU citizens against the lack of supply and/or unaffordable energy prices

The document summarizes the issues for consideration for the short-term as well as the issues for consideration for the longer-term with regard to each priority area, the following of which 
may be effectively supported through the realization of the basic functions of energy security centres:

a) Strengthening cooperation and coordination at EU-level of energy networks to build a panEuropean integrated, interoperable, secure and modern grid.

b) Strengthening the role of ACER (Agency for Cooperation of Energy Regulators) \& ENTSOs (European Network of Transmission System Operators) to develop a more integrated regional and European energy market.

c) Using consumer-centred tools (e.g. labels, information campaigns and long-term education initiatives) to promote energy savings, smart use of energy and fuel switching by energy users.

d) Using market-based instruments to give the right price signals and incentives for energy savings, smart use of energy and fuel switching by energy users, through the emissions trading scheme (ETS), energy taxation and phasing-out of fossil fuel subsidies.

e) Developing a more coordinated European approach towards the licensing and design certification framework for nuclear investments.

f) Implementing the European Strategic Energy Technology Plan (SET-Plan)

g) Launching a dedicated set of large industrial innovation programmes of strategic importance for European energy future.

h) Intensifying efforts in the global energy organisations and initiatives (e.g. IEA, G20, WTO) to promote well-functioning, open, transparent and competitive energy markets, good governance and comprehensive energy policies.

i) Deepening cooperation with consumer countries, including emerging economies, to promote adoption of sustainable energy policies and a shared view on energy security.

j) Increasing transparency. Improving market transparency on network operation and supply which guarantees equal access to information, making pricing more transparent, increasing trust in the market and helping to avoid market manipulation.

k) Providing with guidance on the appropriate tools to facilitate consumer participation in the energy markets through transparency and clarity of information and comparability. [2]

Specific support may be characterized by the following:

- By ensuring the authenticity of the information used, ESCs make an effective contribution to the development of coordination and collaboration. This is particularly important in case of the tasks listed in points a), b), e), f), g), h), i) since authentic information is a basic requirement for good collaboration and successful coordination. Authentic information can be provided through the realization of the first basic function of ESCs. The second basic function, which is the acceleration of the acquisition of practical knowledge, also has a fundamental role in the support of coordination and collaboration. Coordination and collaboration are not only a question of intent: Their implementation requires a considerable amount of expertise. ESCs can support the fast and effective acquisition of this special knowledge with their simulation services.

- The implementation of objectives c), d), j) and k) also requires access to authentic information. This is important not only with regard to the direct use of information. The authentic information provided by ESCs also makes it possible to control the authenticity of the information published by market players, governments and various other institutions, and the existence of such a control will force data providers to adopt an ethical behaviour.

- While the main aim of the second function (the function based on simulation) is to support the preparation and work of decision makers and developers (for example in objectives f), g), h), i)), transparency, information provision and the strengthening of conscious consumer attitudes are ensured through the realization of the third (knowledge transfer) 
function. Access to authentic information has a crucial importance regarding the above objectives, especially the ones listed in point $\mathrm{j}$ ) such as "helping to avoid market manipulation", as well. The realization of effective knowledge transfer has primary importance in strengthening the role of ACER \& ENTSOs in accordance with point b). It must be emphasized that our first priority is not the knowledge transfer development between ACER \& ENTSOs and national (member state) institutions collaborating with them. Rather, we point out the importance of the knowledge transfer taking place between and among member state institutions and market players. This knowledge transfer will ensure the development of a unified view at the EU level and the recognition of the significance of collaboration with ACER \& ENTSOs.

- The implementation of the SET-Plan and launching a dedicated set of large industrial innovation programmes require the coordinated realization of the three basic functions.

- Basically, all the issues for consideration listed in the Stock Taking Document [2] could be supported by knowledge centres one way or another. The objectives set in a)-k) and highlighted above specifically require and cannot lack such support. The matrix below illustrates the strongest connections between the different functions and the issues for consideration.

Table 1. Connections between ESC functions and issues for consideration

\begin{tabular}{cccc}
\hline & \multicolumn{3}{c}{ Functions of ESC } \\
\hline Issues for consideration & A) & B) & C) \\
\hline a) & X & X & X \\
b) & X & X & \\
c) & X & & \\
d) & X & X & \\
e) & X & X & X \\
f) & X & X & \\
g) & X & X & \\
h) & X & X & X \\
i) & X & & \\
j) & X & & \\
k) & X & & \\
\hline
\end{tabular}

Besides the support resulting from the realization of the basic functions, the implementation of issue $\mathrm{j}$ ) also depends on the way ESCs are applied and the regulations in force. Member state and EU level regulations should ensure access to authentic factual information provided by knowledge centres free of charge. Access to simulation and knowledge transfer services should also be made available with one condition: namely, that in the case of certain services users may have to pay a charge.

Apparently, the income resulting from the provision of the above services is not sufficient to finance the operation of knowledge centres. Member state and EU level support are both needed, and the form of support should ensure the independence of knowledge centres. The essay previously referred to [1] discusses in detail the possible forms of financing; here we will only note that it would make sense to develop a normative financing method, where the sums of support are determined in proportion with the income and expenditure of individual member states and the European Union. The independence of knowledge centres, which is a guarantee for their authenticity, should be strengthened with legal regulations. At the nation state level, these institutions should be set up and operated as autonomous public administration institutions. In other words, they should be subordinated only to legislative 
bodies such as Parliament or Congress. In this regard, we should consider the practice applied in the United States concerning the establishment of agencies subordinated to Congress alone. We should note that, as a result of developments in political power relations, in certain member states not even such measures will be sufficient to guarantee independence. In that case we can still count on the authenticating function of the ESC network, through which the not authentically functioning ESC may be excluded from cooperation.

\section{A Few Questions Regarding the Application of Energy Security Centers}

The application of energy security centres to solve the issues raised in the Stock Taking Document has the following guidelines: The energy security centres should be set up in the member states (possibly one in every member state) so that they enjoy autonomy and operate independently from the central government. This is a basic requirement in order to ensure authentic and credible operation. [1] EU level recommendations should also be made to promote the standardization of the legal status of energy security centres.

The authorization of energy security centres for cooperation and information exchange should constitute an integral part of legal regulation. It should be a commonly applied principle that energy security centres may obtain information only from open sources such as the internet, journals, books, conferences, governmental and market data provision etc. The situation is similar regarding the classification of the confidentiality of output information as well: Information provided by energy security centres may not be classified. This rule will no doubt create considerable problems at the level of individual nation states, but desired levels of efficiency cannot be attained otherwise and the missing, or zero information created as a result of classification could create serious problems in simulation procedures supporting the realization of the second basic function.

The virtual solution, according to which the operation of the centres is based primarily on rented ICT capacities, makes possible the application of an exceptionally cost effective solution due to network level cooperation. For example, one or more European super computer centres would be able to serve the entire network of European energy security centres. It is already apparent that there is sufficient band-width available at the level of the entire European Union. What should be concentrated due to the costs involved in interfaces is the simulation capacity required. Therefore, an European energy security simulation centre should be established after the model of The National Exercise Simulation Center (NESC) of Federal Emergency Management Agency (FEMA) of US Department of Homeland Security [7]. As it has been discussed in detail in the essay published in Energy [1], the functionality of FEMA NESC is very close to the second function of energy security centres, which is placing the acquisition of empirical knowledge on qualitatively new foundations. This does not mean that simulation cannot be of divided parameter at the same time. In this regard applications such as IBM Serious Games could play an important role. All the above could be realized on the basis of cloud computing as well. In the case of individual ESCs the goal was the creation of the conditions required for virtual simulation. However, an ESC network would be able to create such an interface and other conditions which would make it possible to employ a mix of live, virtual and constructive simulations.

As the example of the 2009 gas crisis shows, the failure of gas supply can seriously affect electricity supply, domestic heating and industrial heating. The lack of gas supply could also lead to shutting down factories and plants, resulting in serious economic consequences. One of the tasks of the simulation centre may be the modelling and analysis of the impacts of the disruption of gas supply and the exploration of the possible consequences of unexpected 
events. The other task of simulation is the analysis of the effectiveness of measures aiming to reduce or avoid negative impacts. This analysis could provide a basis for the further development of common EU energy policy tools as well.

The interactive conference centre module can also be virtualized or set up as a divided parameter network of accredited conference criteria. In this regard, the application of standardized video conferencing systems is of primary importance. A new element compared to the former concept of energy security centres is the institutionalization of the application of IBM Jam. It means that the European Union could organize EU level IBM Jams on a regular basis to promote the solution of problems emerging during the implementation of the energy strategy and to support innovation. The usefulness of the application of the IBM Jam in this field is supported by a number of references. ${ }^{1}$

\section{Conclusions}

A network of ESCs, outlined only briefly due to the scope of the present paper but discussed in more depth in earlier publications, is capable of satisfying "ripe" objective needs. We should add that these needs do not appear only at the level of the European Union, but at a global level as well. The reason for that is that energy security is a global problem, which can only be solved through global cooperation. Knowledge centres of a different specialization created after the model of the ESC Network will create the background for the qualitative changes envisioned by Manuel Castells [8], according to which the present, oversized national state institutions trembling under the burden of hopeless problem solving will be transformed into development states focusing on planning a desirable future.

We have pointed out that the significance of the creation of an EU level ESC network goes beyond the question of the solution of direct energy security problems and it would create qualitatively new conditions for the implementation of the new energy policy of the European Union. The establishment and development of an ESC network is an EU institutional development task. Its realization requires the support and cooperation of the member states and the creation of an EU level legal regulatory framework.

It must be emphasized that the ESCs should by no means be regarded as research institutions or think-thanks. The task of the latter is to add value information to authentic factual information, while ESCs focus solely on supplying authentic factual information. While it is not possible to support the above argument in more detail in the present paper, the authors hold that there are no significant functional overlaps with regard to other EU or nation state institutions either.

The virtual solution proposed with regard to the establishment of ESCs would create a background for the cost effective development of an EU level ESC network. The European Energy Security Simulation Centre would be the only component of the network tied to specific geographic coordinates, the creation of which could be based on various other, similar EU institutions. The simulation centre should be set up at a location where the critical mass of intellectual and technological potential required for interactive development is already available.

\footnotetext{
1 http://www.globalpulse2010.gov/index.html , http://www.prnewswire.com/news-releases/security-expertscite-need-for-major-policy-changes-to-protect-global-security-in-report-to-nato-and-the-european-union93254954.html , http://www.ibm.com/ibm/responsibility/minijam/overview.html
} 
Based on the above, we recommend the following:

I. The initiation of the development of a European ESC network and its global extension by the EU Presidency.

II. The inclusion of the creation of an ESC network in EU strategies and plans, with special focus on EU Energy Policy and the SET-PLAN.

III. The development and financing of research and development programs and projects required for the creation of an ESC Network.

IV. The simulation of the development of the ICT infrastructure required for the operation and collaboration of ESCs.

As a form of support to the realization of the above, we offer the results of the eSCIT'09 (Global IT Infrastructure of Energy Security Centres) organized on 5-6 October 2009 in Veszprém, Hungary and the expected results of the eSCIT'11 conference, the organization of which is taking place currently.

\section{References}

[1] K. Nagy, “The additional benefits of setting up an energy security centre”, Energy 34, 2009, pp. 1715-1720.

[2] Stock taking document Towards a new Energy Strategy for Europe 2011-2020 http://ec.europa.eu/energy/strategies/consultations/doc/2010_07_02/2010_07_02_energy _strategy.pdf (downloaded 14 December 2010.)

[3] K. Nagy, "The concept of energy security in the light of global security", Chemical Engineering Transactions 18, 2009, pp. 297-302. (Published by AIDC, Roma, 2009., ISBN 978-88 95608-04-4, ISSN 1974-9791)

[4] Commission of the European Communities. Commission staff working document. Accompanying document to the Draft Council Regulation (EC) concerning the notification to the Commission of investment projects into energy infrastructure within the European Community and Repealing Council Regulation (EC) $n^{\circ} 736 / 96$ Executive Summary of the Draft Impact Assessment $\{C O M(2009)$ xxx final $\}$ SEC(2009) xxxx http://ec.europa.eu/energy/strategies/2009/doc/sec_2009_executive_summary.pdf (downloaded 14 December 2010.)

[5] Analytical Methods for Energy Diversity \& Security, Edited by: Morgan Bazilian and Fabien Roques, Elsevier Global Energy Policy and Economics Series 2009. Elsevier Ltd. ISBN: 978-0-08-056887-4

[6] K. Metaxiotis: Intelligent Information Systems and Knowledge Management for Energy: Applications for Decision Support, Usage, and Environmental Protection. Information Science Reference. $1^{\text {st }}$ edition. 2009.

[7] US Department of Homeland Security, Federal Emergency Management Agency (FEMA) The National Exercise Simulation Center (NESC) http://www.fema.gov/news/newsrelease.fema?id=47280 (downloaded 14 December 2010.)

[8] M. Castells, The Information Age - Economy, Society and Culture, Volume III. End of Millennium, Blackwell Publishers, $2^{\text {nd }}$ Edition, 2000, pp. 282-283. 